\title{
The Development of Scientific Reasoning Ability on Concept of Light and Image of Grade 9 Students by Using Inquiry-Based Learning 5E with Prediction Observation and Explanation Strategy
}

\author{
Kittipak Choowong ${ }^{1} \&$ Wittaya Worapun ${ }^{1}$ \\ ${ }^{1}$ Faculty of Education, Mahasarakham University, Thailand \\ Correspondence: Wittaya Worapun, Faculty of Education, Mahasarakham University, Thailand 44000. E-mail: \\ wittaya.wo@msu.ac.th
}

Received: July 15, 2021

Accepted: August 20, $2021 \quad$ Online Published: August 30, 2021

doi:10.5539/jel.v10n5p152

URL: https://doi.org/10.5539/jel.v10n5p152

\begin{abstract}
The purposes of this research were 1) to develop student's scientific reasoning ability on the concept of light and image at a criterion of 70 using inquiry-based learning $5 \mathrm{E}$ with prediction observation and explanation strategy and 2) to compare students' scientific learning achievement on the concept of light and image after using inquiry-based learning $5 \mathrm{E}$ with prediction observation and explanation strategy. The target groups were 22 students of grade 9 selected by a purposive sampling method. The research instruments were lesson plans, achievement test, scientific reasoning ability test, scientific reasoning ability observation form, and scientific reasoning ability interview form the statistics used in data analysis were mean, percentage, and t-test. The results showed that 1) the scientific reasoning ability in cycles 1,2 , and 3 . There were 6,13 , and 21 students who passed their criteria of $70 \%$ of the full score in each learning cycle, respectively. 2) Students' learning achievement after learning with the learning management was significantly higher than the establishment at a criterion of 70 at a statistical level of 05 .
\end{abstract}

Keywords: scientific reasoning ability, inquiry-based learning 5E, prediction observation, explanation strategy

\section{Introduction}

In the 21st century, there are changes in the processes of sciences instruction due to the influences of information technology. Advance in technology also leads to the rise of online community and non-boundary knowledge transference. This leads to the scientific process in finding information since it helps learners to adapt to the world of changes (Nuangchalerm, 2015; Nuangchalerm et al., 2016; Nuangchalerm, 2017). In terms of sciences learning management issued in Thailand 2008 educational core curriculum, scientific abilities are issued to be used in real-life, education, and career. These abilities include creative thinking, reasoning thinking, analytical thinking, scientific skills, and scientific learning skills (The Ministry of Education, 2017).

One of the scientific learning skills is scientific reasoning ability which is an important skill scientist used in illustrating experiments (Kuhn, 1993). The experiment finding should be the result of observation, hypothesis, and test that are presented in summarizing, evidencing, and reasoning - the 3 components of scientific reasoning ability (Suthikul \& Ladachart, 2013). This form of presentation could prevent misconceptions and lead learners to the true concept of what is learning (Lawson, 2004). Moreover, it shows that the average results of Thai students taking the PISA exam in 2000, 2003, 2006, 2009, 2012, 2015, and 2018 were found at 436, 429, 421, $425,444,421$, and 426, respectively. The scores do not reach the OECD standard of 500 and are only considered at level two out of six (The Institute for the Promotion of Teaching Science and Technology, 2020). Lack of scientific reasoning ability results in incapability in identifying scientific issues, providing reasons, and connecting the claims to empirical evidence among Thai learners.

Apart from the PISA exam result, we also observed a sciences class of third grade junior high school and found that the class was mostly lectured with opportunities for discussion. Moreover, it was also found that students' answers were summary of the matter while supporting reasons were missing. In our experiences, learners in Thailand fail to provide reasons to connect the result of the study to the hypothesis when it comes to the classes that require scientific reasoning ability. In a preliminary study, the result of a written test of 3 open-ended questions shows that the score of 22 out of 40 students was found to be below $70 \%$ of the full marks. The test 
result could be interpreted that the participants could not provide reasons to support their claim, cannot raise evidence, fail to make relevant citations, and did not illustrate the relationship between the result and evidence.

The results of the preliminary study are consistent with the PISA exam result, and it was suggested that most Thai learners could not suggest the appropriate conclusion, provide sufficient supporting evidence for their claims while some could provide relevant summary but fail to connect it to the evidence (Suthikul \& Ladachart, 2013). It could be noticed that scientific reasoning ability is important in the processes of learning sciences. Moreover, the components of the ability need to be acquired to develop learners learning processes and to become successful learners who can apply the scientific knowledge in daily life as issued in the Thailand core curriculum. Light and image formation is a topic in sciences courses for 3rd-grade junior high school. The subject content relates to light phenomena in daily life, prism and reflection, image and visual equipment, and brightness and pupils (The Ministry of Education, 2017). In this case, learning activities that allow learners to practice, observe the system of light, and investigate empirical evidence are likely to benefit them. Learning activities should help learners to connect their scientific knowledge and the evidence to provide a reasonable explanation of the phenomena (Nuangchalerm, 2013). These activities are beneficial in contributing to learners' comprehension, scientific reasoning, and learning achievement.

Thailand's core curriculum (2017) also emphasizes using learning management in sciences courses to develop students. The 5E's of inquiry-based learning management could be considered as an effective method in sciences instruction. The learning management was designed in a student-centered pattern. The natures of scientific learning are also the focus of the learning processes along with the core scientific processes. Karnarakpong (2006) claimed that learning management also benefits the processes of thinking at a high level. According to Karplus (1997), the learning processes in the method help learners practice thinking, reasoning, and executing experiments with concepts of sciences, and they also contribute to the ability of information searching of learners. This is consistent with Supautumporn (2018) who found that the 5E's of inquiry-based learning management was effective in developing Thai students' scientific reasoning ability. Moreover, the learning management can also be integrated into other constructivist learning activities such as collective learning management, KM learning management, prediction strategies, observation and explanation (POE), and peer-learning activities.

The Predict-Observe-Explain (POE) activity is an instructional method designed with the principles of 5E inquiry-based learning management. Particularly, POE consists of three main processes namely 1) prediction - the predicting activities for outcome and situation of the problems that demand learners to provide reasons to support their idea, observation-the answer-seeking activity using experiments, 2) observations - activities to prove the hypothesis derived by problem analysis, and 3) explanation - the inquiry activities to check the summary of the experiment which demands learners to provide explanations of how the results relate to each other (The Institute for the Promotion of Teaching Science and Technology, 2020). White and Gunstone (1992) suggested that the POE is a method that encourages reasonable discussion and idea-sharing among peers and teachers in the classes, and it is also beneficial for the development of scientific reasoning ability (Sapasuntikul, 2015).

Scientific reasoning ability refers to the ability to illustrate the relationship between reasons using empirical evidence obtained by scientific processes e.g., observation, experiment, survey, and inspection that lead to the conclusion. There are 3 components of the ability including 1) conclusion - the summary that could explain and ensure phenomena, 2) evidence - the results derived from scientific processes such observation, experiment, and inspection used to support the conclusion, and 3) claiming - the explanation of the relationship between conclusion and empirical supportive evidence using data, principles, rules, and theories.

Inquiry-based learning $5 \mathrm{E}$ with prediction observation and explanation strategy learning management is a set of activities that integrates Inquiry-based learning $5 \mathrm{E}$ to the POE. The detail of the activities can be seen below.

At the engagement process, a prediction strategy is used as a supportive activity. Teachers can introduce the class by informing class purposes and use role-playing situations to engage learners' interest and let them recall the information instructed in the previous classes. Students might be asked to predict the outcomes of the simulated situations or the potential results of the study. The record of prediction of each student could be randomized to be presented in the classes to stimulate students for other sessions of learning.

At the exploration stage, observation is used in the activity by allowing students to find the solution to the situation using observation, experiment, and self-inspection to gather data and empirical evidence. The activity should be student-centered giving students to learn by practice and teachers to shift their role to be advisors.

At the explanation process, learners are expected to present their experimental data in discussable manners. The 
results are discussed to investigate whether they are supporting or against the prediction. The roles of teachers in this stage are to discuss, raise questions, share opinions, and summarize using leading questions.

In the elaboration process, teachers raise situations or scientific issues related to the result of the experiments to let learners synthesize their knowledge by comparing the information obtained in the class to a similar situation. The students should be given opportunities to discuss and share opinions toward the raised situations. This could illustrate the wilder picture of what is learned in the class.

In the last stage of evaluation, students should evaluate their knowledge learned in the classes using speaking and writing ability. The roles of the teachers are to observe, evaluate, and ensure the improvement of the students.

The previous studies suggest that Inquiry-based learning $5 \mathrm{E}$ with prediction observation and explanation strategy could be potential learning management that contributes to the understanding of scientific processes especially for scientific reasoning ability which is an important skill in learning of 21 st century. In the current study, learning management was employed to develop students' scientific reasoning ability and learning achievement in the Thai context. The learning unit of Light and Image formation in sciences course of 3rd-grade junior high school was chosen as it was appropriate for the integrated learning management to be applied. The main expected outcomes are the students' scientific reasoning ability and learning outcomes of the learning unit.

\section{Objectives}

1) To develop students' scientific reasoning ability on the concept of light and image at a criterion of $70 \%$ by using inquiry-based learning $5 \mathrm{E}$ with prediction observation and explanation strategy

2) To compare students' scientific learning achievement on the concept of light and image at a criterion of $70 \%$ after using inquiry-based learning $5 \mathrm{E}$ with prediction observation and explanation strategy

\section{Method}

The study was conducted in a classroom action research design along with the principle of Kemmis and McTaggart (1992). There were 4 processes in the design including planning, action, observation, and reflection which can be illustrated by the figure below.

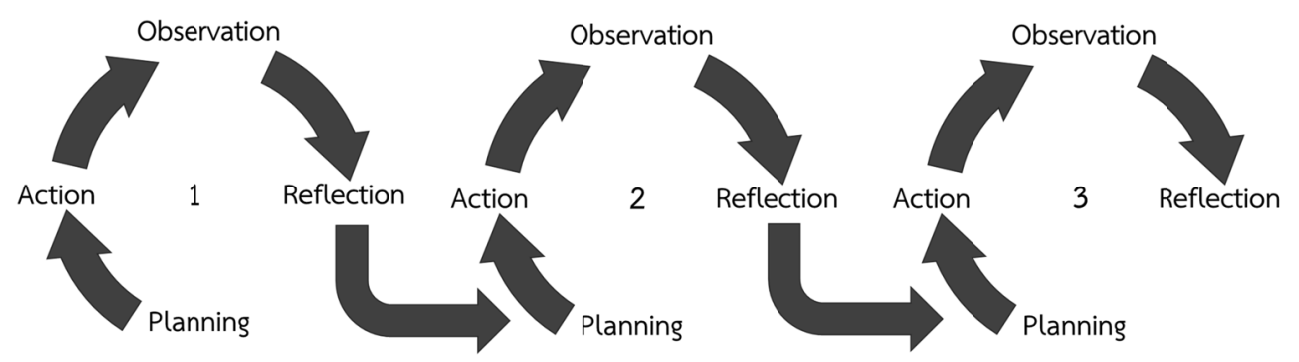

Figure 1. The processes of classroom action research

\subsection{Target Group}

The samples were 22 3rd grade junior high school students in 3/8 class, Kanlayanawat School. The class was selected by the purposive sampling method. A placement test with the criterion of 70 was employed to the class. There were 40 students in the class and 22 of them fail to reach the criterion. Therefore, they were chosen as the samples of the current study.

\subsection{Research Instruments}

1) An Inquiry-based learning $5 \mathrm{E}$ with prediction observation and explanation strategy learning management consists of 9 instructional plans. Plans 1-3 were employed in the first learning cycle. The plans include the content of the natures of light and vision, the relationship between the angle of reflection and angle of incidence, and mirror-image formation. Plans 4-6 were employed in the second learning cycle. The contents relate to the relationship between the angle of deviation and angle of incidence, light reflection, and lens image formation. Plans 7-9 were employed in the third learning cycle The contents relate to light phenomena, visual equipment, and brightness and visualization. The learning management was verified by 5 experts to have $4.59-4.77$ of 
appropriateness index.

2) To assess students' performance, a scientific reasoning ability test was developed. The content of the test is related to light and image formation. The test was a two-tier written test in 3 sections of 3 question items. The Item-Objective Congruence (IOC) of 5 experts indicates $0.60-1.00$ of correlation between the questions and scientific reasoning ability.

3) To observe students' behaviors, a structured observation form was employed in the study. The form was used during the activity to study the scientific reasoning ability of students. The Item-Objective Congruence (IOC) of 5 experts indicates 1.00 of correlation between the from and the observed behaviors.

4) To provide a qualitative point of view to the result, a structured interview form was used after the third learning cycle. The questions cover the components of scientific reasoning ability. The Item-Objective Congruence (IOC) of 5 experts indicates $0.60-1.00$ of correlation between the questions and scientific ability.

5) To assess students' learning achievement, a set of 20 question items designed in 4 multiple-choice tests was employed as a posttest. The Item-Objective Congruence (IOC) of 5 experts indicates $0.60-1.00$ of correlation between the question items and the expected scientific reasoning ability.

\subsection{Data Collection}

The study was operated in a classroom action research design. 3 learning cycles were executed as follows.

Plans 1-3 were employed in the first learning cycle. The plans include the content of the natures of light and vision, the relationship between the angle of reflection and angle of incidence, and mirror-image formation. Plans 4-6 were employed in the second learning cycle. The contents relate to the relationship between the angle of deviation and angle of incidence, light reflection, and lens image formation. Plans 7-9 were employed in the third learning cycle The contents relate to light phenomena, visual equipment, and brightness and visualization

In the first learning cycle, instructional plans 1-3 namely natures of light and vision, the relationship between the angle of reflection and angle of incidence, and mirror-image formation were employed.

In the second learning cycle, instructional plans 4-6 namely the relationship between the angle of deviation and angle of incidence, light reflection, and lens image formation were employed.

In the third learning cycle, instructional plans 7-9 namely light phenomena, visual equipment, and brightness and visualization were employed.

Moreover, the observation form was employed to study students' behaviors while learning with developed learning management. The scientific reasoning ability test was employed after each learning cycle ended. After all the learning cycles ended, the interview form and learning achievement test were assigned to the data collection.

\subsection{Data Analysis}

1) The students' scientific reasoning ability was assessed by using the mean score and percentage of the score from the scientific reasoning ability test. Students need to score more than $70 \%$ or more to pass the criteria.

2) The students' scientific reasoning behaviors were analyzed by the mean score of the data gained from the behavior observation form. Five components including (1) note-taking of scientific issues, situations, and phenomena in both spoken and written medium, (2) behaviors in participation of observations, experiments, and class activities, (3) use of data gained from the experiments and activities in drawing conclusion, (4) the inspection of prediction and explanation using evidence gained from experiments and activities, and (5) presentation of conclusion based on empirical evidence, theories, principles in both written and spoken medium were also analyzed.

3) The students' interview was analyzed by a qualitative method to provide recommendations for the further studies. Scientific reasoning ability was the focus of the interview analysis.

4) The students' score from the learning achievement test was analyzed using a one-sample t-test to investigate the students' performance after learning with the learning management with the criterion of 70 .

\section{Result}

\section{Section 1: The analysis of students' scientific reasoning ability development}

The results of the study indicate that $95.46 \%$ of the samples passed the criteria of 70 after learning with the Inquiry-based learning $5 \mathrm{E}$ with prediction observation and explanation strategy learning management. The detail of the data can be seen in Table 1 . 
Table 1 . The participants' scientific reasoning ability after learning in Inquiry-based learning $5 \mathrm{E}$ with prediction observation and explanation strategy learning management

\begin{tabular}{|c|c|c|c|c|c|c|}
\hline \multirow{2}{*}{$\begin{array}{l}\text { Scientific reasoning ability } \\
\text { (full mark of } 18 \text { ) }\end{array}$} & \multirow[t]{2}{*}{$\bar{X}$} & \multirow[t]{2}{*}{$\%$} & \multicolumn{4}{|l|}{$\mathrm{n}$} \\
\hline & & & success & $\%$ & Unsuccess & $\%$ \\
\hline Pretest & 6.73 & 37.37 & 0 & 0.00 & 22 & 100 \\
\hline Learning cycle 1 & 9.86 & 54.80 & 6 & 27.27 & 16 & 72.73 \\
\hline Learning cycle 2 & 12.55 & 69.70 & 13 & 59.09 & 9 & 40.91 \\
\hline Learning cycle 3 & 14.68 & 81.57 & 21 & 95.45 & 1 & 4.55 \\
\hline
\end{tabular}

According to Table 1, the student's average score was $6.73(37.37 \%)$ at the beginning of the experiment. After learning cycle 1, the average score of the students was found at $9.86(54.80 \%)$ while the students' average score improved to $12.55(69.70 \%)$ after learning cycle 2. Lastly, the average score of the students was $14.68(81.57 \%)$ exceeding the criteria of 70 .

The results of the study go in line with students' behavior observation showing the improvement of all five components of behaviors that indicate scientific reasoning ability namely 1) note taking - scientific issues, situation, and phenomena recording in both spoken and written medium, 2) participation-participation in observations, experiments, and class activities, 3) Data uses - the uses of data gained from the experiments and activities in drawing conclusion, 4) Inspection - the inspection of prediction and explanation using evidence gained from experiments and activities, and 5) presentation - the presentation of conclusion based on empirical evidence, theories, principles in both written and spoken medium. Particularly, the observation indicates the improvement of students' behaviors of all components after learning in each learning cycle. The detail of the students' behaviors in each learning cycle can be seen in Figure 2.

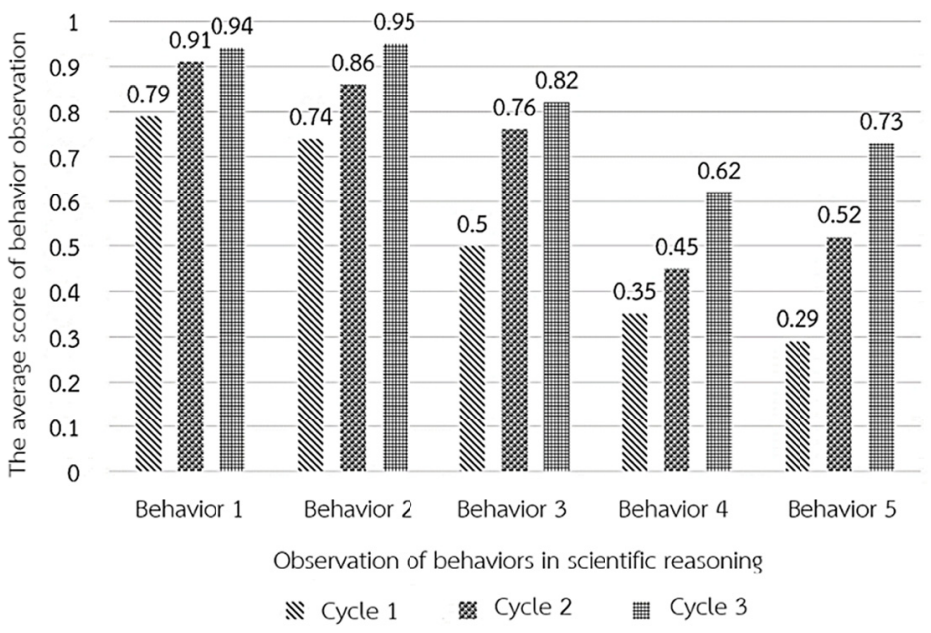

Figure 2. Students' scientific behaviors throughout the study

\section{Section 2: The analysis of student learning achievement}

Students' learning achievement was accessed using a set of 4 multiple choice tests of 20 question items. The data were analyzed using a one-sample t-test with the criteria of 14 (70\%). The result of the study can be seen below.

Table 2. Students' learning achievement after learning with the learning management

\begin{tabular}{lllllll}
\hline \multicolumn{7}{l}{ Students' learning management compared to the criterion of 70} \\
\hline Full mark & Criterion & $\mathrm{N}$ & $\bar{X}$ & S.D. & t & p \\
\hline 20 & 14 & 22 & 15.23 & 2.39 & 2.409 & .025 \\
\hline
\end{tabular}


According to Table 2, it was found that There was a significant difference in the mean score of the students after learning in Inquiry-based learning $5 \mathrm{E}$ with prediction observation and explanation strategy learning management to the criterion of 70 at a statistical level of $.05(\mathrm{p}=0.25)$.

\section{Discussion and Conclusion}

The results of the study indicated that the inquiry-based learning $5 \mathrm{E}$ with prediction observation and explanation strategy learning management led to the continuous improvement of the students' scientific reasoning ability. The score of 6 students $(27.27 \%)$ reached the criterion of 70 in the first learning cycle while there were 13 students $(59.09 \%)$ passing the criterion after the second learning cycle. Finally, there were 21 students $(95.45 \%)$ passing the criterion in the third learning cycle. The results of the study relate to Karnarakpong (2005) who urged that practices in scientific thinking are beneficial in learners' processes of thinking at a high level. To clarify, scientific thinking demands learners to use their reasoning ability in performing scientific activities and generalizing the concept of matters (Karplus, 1997). Moreover, The POE strategies allow learners to use their scientific reasoning ability in discussing issues in classes with peers and instructors (White \& Gunstone, 1992). The processes of learning that support practices of scientific reasoning ability resulted in the development of student's ability in the current study. However, it could not be denied that 1 student could not pass the criterion of 70. In this case, the improvement of the student's ability could be still spotted as his/her score was higher after the third learning cycle. The result of the study supports Sapasantikul (2016) and Supautumbhorn (2018) who also found the improvement of students' ability after learning with a POE strategy-based learning management. The detail of the results in each learning cycle could be discussed below.

In learning cycle 1 , six out of twenty-two students passed the criterion. These students were also found to have enthusiasm in learning, replying to class questions, participating in activities, doing class assignments, and comforting other peers comparing to those who did not pass the test. These behaviors are considered a key component for successful learners (Davis, 1977). The analysis of students' behaviors indicates a high level of behaviors 1 and 2 which are related to drawing scientific conclusions. It could be interpreted that the students could take notes and use the fact to support their claims. However, that average score was torn down might be because of the student's performance in other behaviors of assessment. For example, the behavior in data uses (behavior 3) was found at an average level. In this case, the student could use data gained from experiments and class activities to draw a conclusion. However, some students added personal opinions which are against Toulmin's principle in drawing a scientific conclusion. According to Toulmin (2003), a conclusion must be a synthesis of empirical data and facts. Meanwhile, the behaviors of inspection (behavior 4) and presentation (behavior 5) were found at a low level. It could be interpreted that lack of ability to compare the results of experiment and prediction and present a conclusion that is relevant to the evidence results in a low students' average score and a low number of students who passed the criterion in the first learning cycle.

In learning cycle 2, class activities were adjusted based on problems found in the first cycle, and it resulted in 13 out of 22 students passing the criterion. It was also noticed that students were more eager to learn, participate in activities and experiments, and answer questions. The result of the study is also supported by the data in the behavior observation. In detail, behaviors 1 and 2 were clearly spotted since most students could record important information in the class experiment, and they also took part in the experiment. Moreover, in key behavior 3, the students could use data from class activities and experiments to support their claims. However, some of the information was found to be from an online source which was not relevant to the purpose of the classes. In terms of inspection and data presentation, it was found that the students could compare the results of the class experiment to the prediction using empirical data, rules, and principles. They could also present the summary from a scientific point of view using appropriate information to explain the issues found in activities. Nevertheless, some students still use irrelevant evidence in both inspection and result presentation. The improvement of class scientific learning behaviors results in the increasing number of students passing the criterion after learning cycle 2 .

In learning cycle 3 , the overall students' scientific reasoning ability continued to improve as 21 out of 22 students were found to pass the criterion of 70 . The result of the study is relevant to the behavior observation. At this point of data collection, most students were found to have all key behaviors in scientific learning. In detail, the students could synthesize important information from activities, participate in activities with knowledge of sciences, support their conclusions using only scientific data from activities, experiments, and principles, generate the concept of matters using scientific evidence to compare the prediction and result, and present information along with scientific processes. These behaviors were evidenced by the fact that $95.45 \%$ of students passed the criterion after learning in learning cycle 3. Moreover, in the case of a student who did not pass the criterion, the improvement could still be notified. In detail, the student's scores were 6 in the first cycle, 8 in the 
second cycle, and 12 in the third cycle. In addition, it could be noted that the behaviors of note-taking, class participation, and data uses were spotted in the student after the third learning cycle. Thus, the inspection and presentation behaviors were the problems of the student.

In conclusion, it could be summarized that the inquiry-based learning $5 \mathrm{E}$ with prediction observation and explanation strategy learning management led to the development of students' scientific reasoning ability. Statistically, the learning management results in $95.45 \%$ of students passing the criterion after the third cycle, and it also leads to continuous improvement of one who did not pass the criterion. Moreover, five key behaviors indicating scientific reasoning ability were found in most students after completing all cycles in the learning management. It could be interpreted that continuous practice in each learning cycle played an important role in generating behaviors for students which contribute to their scientific reasoning ability (Khamanee, 2014).

In terms of the effects of learning management on students' learning achievement, it was found that the average score of the students passed the criterion of 70 at a statistical level at .05 . Particularly, the average score was at $15.23(76.15 \%)$ out of 20 after learning in the inquiry-based learning 5E with prediction observation and explanation strategy. It could be implied that the learning management led to the development of students' scientific reasoning ability. The results of the study could be discussed as follows.

First, learning management was developed based on a learning-centered approach that emphasizes thinking practice and reasoning ability. Nuangchalerm (2015) suggested that learners should be instructed to develop their processes of thinking as it is a key component of sciences learning. The instructional activities that allow them to take part in the scientific experiment would let them grow their knowledge along with constructivism theory continuous learning and self-practice. The constant practices would eventually lead to better processes of thinking. The result of the study is relevant to Thukeaw (2018) who also found the development of students' learning achievement after learning in learning management developed in POE design.

Secondly, the effectiveness of the learning management could be considered as a result of class regulation. It could be difficult for young learners to concentrate on such complicated processes of scientific experiments. Therefore, to generate expected behaviors for students, class regulation should be respected (Wejchayaluk, 2016; Jindanurak, 2018). For example, students were not allowed to make inappropriate noise in classes for it disrupts others in learning. Moreover, online learning source is also important for learning in the 21 st century. During the process of data collection, we encouraged the students to learn by themselves by providing useful video links that related to class content.

In conclusion, it could be summarized that the inquiry-based learning $5 \mathrm{E}$ with prediction observation and explanation strategy learning management led to the development of students' learning achievement. With regulation and support of learning in the 21st century, learning management was proved to be beneficial in developing sciences learning achievement for students in Thailand. The results of the study could be concluded that the inquiry-based learning $5 \mathrm{E}$ with prediction observation and explanation strategy learning management was effective in both developing students' scientific reasoning ability and learning achievement (Prachagool \& Nuangchalerm, 2019). Therefore, learning management is a potential alternative for instructing sciences classes. The learning management should be applied in a 1-2-hour class to let students take time to learn about the components of scientific reasoning and develop their ability to use it in learning sciences.

\section{Recommendation}

In terms of a pedagogical point of view, scientific reasoning ability is not familiar among young learners. Therefore, instructors should illustrate the components of the ability and how they have connected from the ability before beginning activities in the learning management. For further studies, the scientific reasoning ability should be assessed in each component as it could help scholars to focus on improving students' abilities in each component.

\section{References}

Davis, K. (1977). Human behavior at work. New York: McGraw - Hill.

Jindanurak, T. (2018). Classroom management for developing 21st-century learning skills. Nonthaburi, Thailand, Sukothai Thummathirat University.

Karnarakpong, S. (2006). 5E inquiry-based learning activities for mathematics. Bangkok, Thailand: Tharnauksorn Press.

Karplus, R. (1997). Science Teaching and Development of Research in Science Teaching. Journal of Science Education, 199(4), 196-175. 
Khammanee, T. (2014). Teaching sciences: Effective learning management. Bangkok, Thailand: Chulalongkorn University Press.

Kuhn, D. (1995). Science as argument: Implications for teaching and learning scientific thinking. Journal of Science Education, 77(3), 319-337.

Lawson, A. E. (2004). The Nature and Development of Scientific Reasoning: A Synthetic View. International Journal of Science and Mathematics Education, 2(1), 307-338. https://doi.org/10.1007/s10763-004-3224-2

Nuangchalerm, P. (2013). Engaging nature of science to preservice teachers through inquiry-based classroom. Journal of Applied Science and Agriculture, 8(3), 200-203.

Nuangchalerm, P. (2015). Learning in the 21st century. Bangkok, Thailand: Chulalongkorn University Press.

Nuangchalerm, P. (2017). Relationship between preferred and actual opinions about inquiry-based instruction classroom. European Journal of Science and Mathematics Education, 5(1), 67-73. https://doi.org/10.30935/scimath/9498

Nuangchalerm, P., Dostál, J., \& Luo, X. (2016). Investigating pre-service secondary science teachers' practices about inquiry-based instruction during school practicum. Chemistry: Bulgarian Journal of Science Education, 25(4), 487-495.

Prachagool, V., \& Nuangchalerm, P. (2019). Investigating understanding the nature of science. International Journal of Evaluation and Research in Education, 8(4), 719-725.

Sapasantikul, K. (2016). Effects of chemistry teaching strategy using the predict-observe-explain sequence on ability in scientific explanation making and rationality of tenth-grade students. Bangkok, Thailand: Chulalongkorn University.

Supautumporn, P. (2018). Effects of using 5e learning cycle model on scientific rational thinking abilities and scientific creative thinking abilities of lower secondary school students in Chulalongkorn university demonstration secondary school. Bangkok, Thailand: Chulalongkorn University Press.

Suthikul, L., \& Ladachart, L. (2013). Fourth-grade students' scientific reasoning. Naresuan University Journal, 21(30), 107-123.

The Institute for the Promotion of Teaching Science and Technology. (2010). The structure of international standardized high school sciences classrooms based on The Institute for the Promotion of Teaching Science and Technology 2012. Bangkok, Thailand: The Institute for the Promotion of Teaching Science and Technology.

The Institute for the Promotion of Teaching Science and Technology. (2020). The summary of Thailand PISA exam results. Retrieved 15 August 2020 from https://pisathailand.ipst.ac.th/pisa2018- summary- result/

The Ministry of Education. (2017). Indicators of sciences subject in core curriculum 2008. Bangkok, Thailand: Ministry of Education.

Thukeaw, A. (2018). The effect of learning activities by the predict observe explain the method on science achievement and scientific process skills of Mathayomsuksa 2 students. Nakonsawan, Thailand: Rajabhat Nakhonsawan University.

Toulmin, S. F. (2003). The uses of argument. Cambridge: Cambridge University Press. https://doi.org/10.1017/CBO9780511840005

Wejchatalak, Y. (2016). Classroom management for supporting learning in the 21st century. Journal of Graduate School Sakon Nakhon Rajabhat University, 13(61), 11-20.

White, R. T., \& Gunstone, R. F. (1992). Probing understanding. London: Falmer Press.

\section{Copyrights}

Copyright for this article is retained by the author, with first publication rights granted to the journal.

This is an open-access article distributed under the terms and conditions of the Creative Commons Attribution license (http://creativecommons.org/licenses/by/4.0/). 